\title{
FREQÜÊNCIA DA FERTIRRIGAÇÃO DA BANANEIRA PRATA-ANÃ COM NITROGÊNIO E POTÁSSIO APLICADOS POR MICROASPERSÃO
}

\author{
AMILTON G. GUERRA ${ }^{1}$, JOSÉ R. ZANINI ${ }^{2}$, WILLIAM NATALE ${ }^{3}$, LUIZ C. PAVANI ${ }^{2}$
}

RESUMO: $O$ experimento teve por objetivo avaliar a freqüência de fertirrigações com nitrogênio e potássio aplicadas por microaspersão na cultura da bananeira (Musa sp. AAB), cultivar Prata-Anã, durante dois ciclos de cultivo. O experimento foi conduzido na Área Demonstrativa e Experimental de Irrigação do Departamento de Engenharia Rural da FCAV/UNESP, Jaboticabal - SP. Utilizou-se do delineamento em blocos ao acaso, com parcelas subdivididas e cinco repetições, constituídas por quatro modalidades de aplicação de fertilizantes (adubação via solo, fertirrigação mensal, fertirrigação bimestral e fertirrigação trimestral) e duas doses de nitrogênio e potássio, correspondendo a $100 \%$ (dose 1) e $50 \%$ (dose 2) da dose recomendada de nutrientes. A fertirrigação mensal proporcionou peso de cachos, peso de pencas e produtividades superiores à adubação convencional e menor acidez total titulável dos frutos em relação à fertirrigação trimestral; a redução de $50 \%$ das doses de $\mathrm{N}$ e $\mathrm{K}$ não exerceu efeito sobre a produção e qualidade dos frutos.

PALAVRAS-CHAVE: banana, Musa sp, irrigação.

\section{FREQUENCY OF FERTIGATION WITH NITROGEN AND POTASSIUM APPLIED BY MICROSPRINKLER SYSTEM ON PRATA-ANÃ BANANA PLANT}

SUMMARY: This study was carried out in order to evaluate the effect of fertigations with nitrogen and potassium applied by microsprinkler system on the plantation of Prata-Anã banana (Musa sp $\mathrm{AAB}$ ), during two growing seasons, under field conditions. The experiment was carried out in the irrigation area of the Department of Agricultural Engineering, FCAV/UNESP - Jaboticabal, São Paulo State, Brazil. It was used a completely randomized block design in split plot with five replications. The treatments studied were composed of four fertilizer application modalities (side dressing fertilization, monthly fertigation, bimonthly fertigation and three monthly fertigation) combined with two rates of nitrogen and potassium, corresponding to $100 \%$ (rate 1) and $50 \%$ (rate 2) of the recommended rates based on the soil analysis. Monthly fertigation promoted bunch weight and yield higher than side dressing fertilization and lower acidity of the fruits than three monthly fertigation; reducing $50 \%$ the doses of $\mathrm{N}$ and $\mathrm{K}$ did not affect yield and quality of the banana fruit.

KEYWORDS: banana, Musa sp, irrigation.

\section{INTRODUÇÃO}

A bananeira (Musa sp L.) é uma planta de regiões tropicais e subtropicais, cujo centro de origem é o continente asiático, exigente em água nos períodos de estiagens com temperaturas e evaporações elevadas. A banana é a fruta preferida, sendo o quarto produto mais consumido no mundo, ficando atrás do trigo, milho e arroz. O Brasil destaca-se como o seu maior consumidor e, segundo a FAO (2002), é o terceiro maior produtor (10\% do total mundial), com produção em torno de 6,3 milhões de toneladas. A área ocupada pela cultura é de 480 mil hectares, concentrando-se na Bahia, Ceará, São

\footnotetext{
${ }^{1}$ Pesquisador, Doutor, EMPARN, Natal - RN, Fone: (0XX84) 221.2341, e-mail: amiltonguerra@bol.com.br

${ }^{2}$ Prof. Dr., Departamento de Engenharia Rural, Faculdade de Ciências Agrárias e Veterinárias, UNESP, Jaboticabal - SP.

${ }^{3}$ Prof. Dr., Departamento de Solos, Faculdade de Ciências Agrárias e Veterinárias, UNESP, Jaboticabal - SP.

Recebido pelo Conselho Editorial em: 28-8-2002

Aprovado pelo Conselho Editorial em: 10-2-2004
} 
Paulo, Rio Grande do Norte, Santa Catarina e Rio de Janeiro, com 78\% da produção; a região Sudeste participa com 26,4\% da produção nacional, sendo São Paulo o maior produtor (IEA, 1997).

A produção paulista está concentrada no Vale do Ribeira, com 3.341 produtores explorando 38.912 ha, da qual a cultivar Prata-Anã ocupa apenas 240 ha, equivalente a 7,2\% da área total (TONET, 1997, citado por PIZA JÚNIOR, 1997). A infestação da bananeira pelo Mal-do-Panamá naquela região forçou a substituição parcial e, em alguns casos, até total das cultivares, dificultando seu aperfeiçoamento tecnológico (PIZA JÚNIOR, 1997).

A fertirrigação é uma técnica utilizada há anos pelos agricultores dos Estados Unidos, Israel e Itália, tornando-se de uso generalizado nesses países com o desenvolvimento de sistemas de irrigação modernos. No Brasil, o emprego da fertirrigação é recente, e em geral mais adotada pelos produtores que utilizam irrigação localizada. Essa técnica ajusta-se bem à fertilização da bananeira, que é exigente em nutrientes, com maior expressão para potássio e nitrogênio (SOTO, 1992; BORGES et al., 1997; GOMES \& NÓBREGA, 2000).

O nitrogênio e o potássio são os elementos aplicados com maior freqüência via água de irrigação; enquadram-se perfeitamente a essa técnica devido à alta mobilidade no solo e quase $100 \%$ de solubilidade em água. Com o uso da fertirrigação, pode-se parcelar a aplicação dos fertilizantes nitrogenados e potássicos de acordo com a demanda das culturas. Com o parcelamento da adubação nitrogenada, pode-se aumentar a eficiência de uso do nitrogênio, reduzindo as perdas por lixiviação (COELHO, 1994).

A participação do potássio na bananeira está mais diretamente associada à produção de cachos, pencas, produtividade, maior resistência pós-colheita e qualidade dos frutos. A bananeira exige elevadas quantidades de potássio para atingir níveis satisfatórios de produtividade. Segundo LOPEZ \& ESPINOSA (1995), utilizando adubação convencional, as maiores produtividades foram obtidas com oito aplicações e doses anuais de $\mathrm{K}_{2} \mathrm{O}$ variando de 600 a $750 \mathrm{~kg} \mathrm{ha}^{-1}$.

O objetivo deste estudo foi avaliar o efeito da freqüência da fertirrigação (via microaspersão) com nitrogênio e potássio em relação à adubação convencional (via solo), na produção e qualidade dos frutos da bananeira Prata-Anã.

\section{MATERIAL E MÉTODOS}

O experimento foi desenvolvido na Área Demonstrativa e Experimental de Irrigação do Departamento de Engenharia Rural da FCAV/UNESP, no município de Jaboticabal - SP. O clima da região, segundo o sistema de classificação de Köeppen, é do tipo Cwa, caracterizado como subtropical com chuvas de verão, inverno relativamente seco e temperatura média do mês mais quente (outubro) de $22{ }^{\circ} \mathrm{C}$ e do mês mais frio (junho) $16{ }^{\circ} \mathrm{C}$. As características químicas do solo estão na Tabela 1.

TABELA 1. Características químicas do solo da área experimental cultivado com bananeira Prata-Anã, nas profundidades de $0-20$ e $20-40 \mathrm{~cm}$.

\begin{tabular}{ccccccccccc}
\hline $\begin{array}{c}\text { Profundidade } \\
(\mathrm{cm})\end{array}$ & $\mathrm{pH}$ & $\begin{array}{c}\mathrm{M} . \mathrm{O} . \\
\mathrm{CaCl}_{2}\end{array}$ & $\begin{array}{c}\mathrm{g} \mathrm{dm}^{-3} \\
\begin{array}{c}\text { (resina) } \\
\mathrm{mg} \mathrm{dm}^{-3}\end{array}\end{array}$ & $\begin{array}{c}\mathrm{K} \\
----\end{array}$ & $\mathrm{Ca}$ & $\mathrm{Mg}$ & $\mathrm{H}+\mathrm{Al}$ & $\mathrm{SB}$ & $\mathrm{CTC}$ & $\mathrm{V}$ \\
\hline $0-20$ & 5,7 & 13 & 44 & 0,8 & 31 & 13 & 22 & 44,8 & 66,8 & 67 \\
$20-40$ & 5,5 & 14 & 22 & 1,1 & 26 & 10 & 25 & 37,1 & 62,1 & 60 \\
\hline
\end{tabular}

A cultivar utilizada no experimento foi a Prata-Anã e o plantio realizado em 24-2-1999, com mudas produzidas in vitro. As práticas culturais freqüentemente utilizadas em bananal, como desbaste, desbrota, desfolha, eliminação do coração, eliminação da última penca, controle fitossanitário e 
controle de plantas daninhas foram realizados conforme as necessidades da cultura (EPAMIG, 1996 e ALVES, 1999).

O delineamento experimental foi o de blocos ao acaso, com parcelas subdivididas em cinco repetições, constituídas por quatro modalidades de aplicação de fertilizantes: AC-adubação convencional via solo, com aplicações manuais em faixa circular ao redor da planta, em três épocas do ano (agosto, dezembro e fevereiro); FM - fertirrigação mensal; FB - fertirrigação bimestral; FT fertirrigação trimestral.

Para cada modalidade de aplicação, nas subdivisões das parcelas, foram utilizadas duas dosagens do fertilizante nitrogenado e do fertilizante potássico: D1 - dose 100\% dos fertilizantes recomendados segundo RAIJ et al. (1996); D2 - dose 50\% dos fertilizantes.

Os tratamentos receberam nitrato de amônio $(32 \%$ de $\mathrm{N})$ e cloreto de potássio $\left(60 \%\right.$ de $\left.\mathrm{K}_{2} \mathrm{O}\right)$, nas quantidades de 250 e $304 \mathrm{~kg} \mathrm{ha}^{-1}$ de nitrato de amônio, no primeiro e segundo ciclos, e 571 e $673 \mathrm{~kg}$ $\mathrm{ha}^{-1}$ de cloreto de potássio, no primeiro e segundo ciclos, respectivamente, representando a dose 1 $(100 \%)$.

A adubação fosfatada aplicada foi de $20 \mathrm{~kg} \mathrm{ha}^{-1}$ de $\mathrm{P}_{2} \mathrm{O}_{5}$, no primeiro ciclo, e de $50 \mathrm{~kg} \mathrm{ha}^{-1}$ de $\mathrm{P}_{2} \mathrm{O}_{5}$, no segundo ciclo, em todos os tratamentos, utilizando-se como fonte de $\mathrm{P}$, o superfosfato simples. As quantidades de adubo aplicado no experimento foram baseadas em recomendações de RAIJ et al. (1996).

As parcelas foram constituídas por linhas de dez plantas e divididas em subparcelas de cinco plantas, utilizando-se de três plantas para avaliações e duas plantas como bordadura. $\mathrm{O}$ espaçamento utilizado foi de $2,5 \times 2,8 \mathrm{~m}$, numa área útil de $21 \mathrm{~m}^{2}$ por subparcela. Alternadamente às linhas de plantas dos tratamentos, existiam linhas de plantas utilizadas como bordadura lateral, as quais receberam a mesma adubação da dose 1 , sendo a área total do experimento de $3.080 \mathrm{~m}^{2}$.

Utilizou-se do sistema de irrigação por microaspersão, com emissores Dan Sprinkler 2001, com autocompensador de pressão. Segundo o catálogo do fabricante, a vazão é praticamente constante $\left(35 \mathrm{~L} \mathrm{~h}^{-1}\right)$, para pressão de 12 a $40 \mathrm{~m}$ de coluna d'água e diâmetro de alcance dos microaspersores de $5 \mathrm{~m}$, instalando-se um microaspersor por cova.

A fertirrigação foi realizada com um tanque de derivação de fluxo, com capacidade de $70 \mathrm{~L}$, sendo desviado $100 \%$ do fluxo de cada parcela pelo seu interior.

No período do experimento, a precipitação pluviométrica foi de $1.544,1 \mathrm{~mm}$, e a lâmina de irrigação suplementar foi de $383,0 \mathrm{~mm}$, no primeiro ciclo, e precipitação de $197,7 \mathrm{~mm}$ e a lâmina de irrigação suplementar de $497 \mathrm{~mm}$, no segundo ciclo. A necessidade de água foi obtida pelo cálculo da evapotranspiração, baseando-se nos dados de evaporação no tanque Classe A e precipitação, conforme processo descrito por OLLITA (1977), por meio da seguinte expressão:

$$
\mathrm{V}=\frac{[(\mathrm{ECA} \mathrm{Kp} \mathrm{Kc})-\mathrm{P}] \mathrm{A} \mathrm{Kr}}{\mathrm{Ef}}
$$

em que,

$\mathrm{V}$ - volume de água a ser aplicado, $\mathrm{L} \mathrm{dia}^{-1}$;

ECA - evaporação no tanque Classe A, mm;

$\mathrm{Kp}$ - fator de multiplicação de leitura do tanque $=0,75$;

Kc - coeficiente de cultura (Tabela 2);

$\mathrm{P}$ - precipitação ocorrida no período, $\mathrm{mm}$;

A - área definida pelo espaçamento entre plantas $\left(\mathrm{m}^{2}\right)=2,5 \times 2,80 \mathrm{~m}$, e

Ef - eficiência de irrigação $(0,8)$. 
Para o cálculo da porcentagem de área molhada pelo efeito da irrigação $(\mathrm{Kr})$, adotando o valor máximo igual a um, utilizou-se da expressão de KELLER \& KARMELLI (1975): $\mathrm{Kr}=\% \mathrm{AC} / 0,85$, sendo AC a área do solo coberta pelas plantas. Para os coeficientes de cultura (Kc), foram adotados valores de acordo com o desenvolvimento da cultura (Tabela 2), para o primeiro ciclo (DOORENBOS \& KASSAM, 1979). No segundo ciclo, adotou-se o valor máximo de Kc igual a 1,10.

TABELA 2. Coeficiente de cultura (Kc) da bananeira em regiões de clima tropical.

\begin{tabular}{|c|c|c|c|c|c|c|c|c|c|c|c|c|c|c|c|}
\hline Mês & 1 & 2 & 3 & 4 & 5 & 6 & 7 & 8 & 9 & 10 & 11 & 12 & 13 & 14 & 15 \\
\hline Fases & \multicolumn{6}{|c|}{ Rebroto } & \multicolumn{5}{|c|}{ Floração } & \multicolumn{4}{|c|}{ Colheita } \\
\hline $\mathrm{Kc}$ & 0,40 & 0,40 & 0,45 & 0,50 & 0,60 & 0,70 & 0,85 & 1,00 & 1,10 & 1,10 & 0,90 & 0,80 & 0,80 & 0,95 & 1,00 \\
\hline
\end{tabular}

Considerando-se a ocorrência de ventos moderados na região $\left(175-425 \mathrm{~km} \mathrm{dia}^{-1}\right)$, umidade relativa média do ar de 40 a $70 \%$ e a instalação do tanque em área com vegetação baixa, adotou-se 0,75 como valor de $\mathrm{Kp}$.

Os intervalos entre as irrigações foram de três e de quatro dias, alternadamente.

A colheita foi iniciada em 5-5-2000 e 7-9-2000, no primeiro e segundo ciclos, respectivamente. As avaliações físicas e químicas dos frutos foram realizadas sistematicamente com a maturação, em quatro frutos, retirados ao acaso na segunda penca do cacho, conhecida como penca-índice.

Os frutos foram pesados em balança de precisão e a medida do diâmetro realizada com paquímetro digital de precisão $1: 10$. Os frutos foram armazenados à temperatura ambiente de $16,4^{\circ} \mathrm{C}$, para a média das mínimas, e $22,9{ }^{\circ} \mathrm{C}$ para a média das máximas, no período de 60 dias após início da colheita e $12,6{ }^{\circ} \mathrm{C}$ para a média das mínimas, e $21,4{ }^{\circ} \mathrm{C}$ para a média das máximas no período de 95 dias após início da colheita, no primeiro e segundo ciclos, respectivamente.

Os teores de sólidos solúveis totais foram determinados em quatro frutos de cada penca-índice por meio de leituras diretas em refratômetro (TRESSLER \& JOSLYN, 1961).

A acidez total titulável, expressa em gramas de ácido cítrico por 100 gramas de polpa, foi determinada em duas amostras, contendo cada uma $30 \mathrm{~g}$ de polpa homogeneizada em liqüidificador. Após adicionarem-se $50 \mathrm{~mL}$ de água destilada e agitação por 5 minutos, foram tituladas com solução padronizada de hidróxido de sódio a $0,1 \mathrm{~N}$, tendo como indicador a fenolftaleína a $0,1 \%$ (TRESSLER \& JOSLYN, 1961), sendo o $\mathrm{pH}$ determinado em amostra com $30 \mathrm{~g}$ da polpa em repouso por 30 minutos, após homogeneização em liqüidificador.

Os resultados foram submetidos à análise de variância e de confrontação de médias pelo teste de Tukey, empregando-se o módulo GLM (General Linear Models) do Statistical Analysis System - SAS (FREUD \& LITTELL, 1981).

\section{RESULTADOS E DISCUSSÃO}

A análise de variância dos dados não revelou interferência significativa das formas de fertilização, das doses nem de suas interações sobre o período do plantio ao florescimento, diâmetro do pseudocaule e número de pencas por cacho, nos dois ciclos avaliados (Tabela 3). No entanto, esses parâmetros podem ter sido prejudicados pelas baixas temperaturas e geadas ocorridas durante $o$ segundo ciclo, conforme se pode verificar pelas temperaturas mínimas (Figura 1), e devem ter contribuído para o atraso do florescimento da bananeira em relação ao primeiro ciclo, conforme comenta ALVES (1999). Quanto ao diâmetro do pseudocaule, apesar de as freqüências adotadas não 
exercerem efeitos significativos, BORGES et al. (1994) e BORGES et al. (1997) afirmam que essa variável é, na maioria das vezes, mais dependente do espaçamento e da densidade populacional que propriamente das variações nas formas de adubação do solo.

Houve efeito significativo quanto aos dias do plantio à colheita, em relação às duas variáveis no segundo ciclo; a FM apresentou menor número de dias do que os tratamentos AC e FB.

$\mathrm{O}$ número de pencas por cacho não mostrou resultados significativos quanto às freqüências e doses de $\mathrm{N}$ e $\mathrm{K}$ usadas nos dois ciclos de cultivo (Tabela 3). Essa característica é inerente à cultivar e mostra pouca variação no campo (BORGES et al., 1994; SILVA et al., 1999).

TABELA 3. Efeitos da freqüência da fertirrigação nitrogenada e potássica em diferentes parâmetros avaliados da bananeira Prata-Anã.

\begin{tabular}{|c|c|c|c|c|c|c|c|}
\hline Estatística & $\begin{array}{l}\text { NDPF } \\
\text { (dias) }\end{array}$ & $\begin{array}{l}\text { NDPC } \\
\text { (dias) }\end{array}$ & $\begin{array}{l}\mathrm{DP} \\
(\mathrm{cm})\end{array}$ & NPC & $\begin{array}{c}\mathrm{PC} \\
(\mathrm{kg})\end{array}$ & $\begin{array}{l}\mathrm{PP} \\
(\mathrm{g})\end{array}$ & $\begin{array}{c}\text { Produtividade } \\
\left(\mathrm{t} \mathrm{ha}^{-1}\right)\end{array}$ \\
\hline \multicolumn{8}{|c|}{ Primeiro Ciclo } \\
\hline Freqüência (F) & $3,17 \mathrm{~ns}$ & $1,50 \mathrm{~ns}$ & $3,14 \mathrm{~ns}$ & $1,87 \mathrm{~ns}$ & $2,74^{*}$ & $2,8^{*}$ & $2,74^{*}$ \\
\hline Dose (D) & $0,60 \mathrm{~ns}$ & $0,19 \mathrm{~ns}$ & $0,03 \mathrm{~ns}$ & $1,00 \mathrm{~ns}$ & $0,73 \mathrm{~ns}$ & $0,01 \mathrm{~ns}$ & $0,01 \mathrm{~ns}$ \\
\hline F x D & $0,91 \mathrm{~ns}$ & $0,85 \mathrm{~ns}$ & $1,11 \mathrm{~ns}$ & $2,25 \mathrm{~ns}$ & $0,83 \mathrm{~ns}$ & $0,54 \mathrm{~ns}$ & $0,54 \mathrm{~ns}$ \\
\hline$\overline{C . V . p a r c e l a}$ & 2,75 & 11,48 & 4,58 & 8,05 & 6,43 & 9,25 & 9,25 \\
\hline C.V. subparcela & 2,03 & 9,13 & 3,56 & 5,19 & 4,23 & 4,23 & 4,23 \\
\hline \multicolumn{8}{|l|}{ Média $(\mathrm{F})$} \\
\hline $\mathrm{AC}$ & 322 & 458 & 14,16 & 7,31 & $7,73 b$ & $1057,18 b$ & $11,04 \mathrm{~b}$ \\
\hline FM & 321 & 449 & 15,23 & 9,17 & $11,23 \mathrm{a}$ & $1224,63 a$ & $16,04 a$ \\
\hline FB & 332 & 458 & 14,91 & 7,98 & $9,11 \mathrm{ab}$ & $1141,21 \mathrm{ab}$ & $13,01 \mathrm{ab}$ \\
\hline FT & 327 & 451 & 15,07 & 7,65 & $8,48 \mathrm{ab}$ & $1109,11 \mathrm{ab}$ & $12,11 \mathrm{ab}$ \\
\hline \multicolumn{8}{|l|}{ Média (D) } \\
\hline D1 & 327 & 454 & 14,85 & 7,60 & & 1110,43 & 12,05 \\
\hline D2 & 325 & 454 & 14,79 & 7,42 & & 1143,89 & 12,12 \\
\hline \multicolumn{8}{|c|}{ Segundo Ciclo } \\
\hline Freqüência (F) & $1,64 \mathrm{~ns}$ & $8,44^{*}$ & $0,57 \mathrm{~ns}$ & $1,34 \mathrm{~ns}$ & $2,69^{*}$ & $2,83^{*}$ & $2,81^{*}$ \\
\hline Dose (D) & $0,01 \mathrm{~ns}$ & $5,02 *$ & $0,44 \mathrm{~ns}$ & $1,91 \mathrm{~ns}$ & $0,34 \mathrm{~ns}$ & $0,01 \mathrm{~ns}$ & $0,04 \mathrm{~ns}$ \\
\hline $\mathrm{F} \times \mathrm{D}$ & $2,01 \mathrm{~ns}$ & $7,85^{*}$ & $0,63 \mathrm{~ns}$ & $2,34 \mathrm{~ns}$ & $1,24 \mathrm{~ns}$ & $0,74 \mathrm{~ns}$ & $0,06 \mathrm{~ns}$ \\
\hline$\overline{C . V . p a r c e l a ~}$ & 7,52 & 2,21 & 6,63 & 7,04 & 4,90 & 14,32 & 8,73 \\
\hline C.V. subparcela & 3,56 & 2,33 & 4,21 & 6,24 & 3,06 & 11,36 & 5,53 \\
\hline \multicolumn{8}{|l|}{ Média (F) } \\
\hline $\mathrm{AC}$ & 417 & $594 a$ & 16,98 & 7,25 & $7,70 \mathrm{~b}$ & $1.061,75 \mathrm{~b}$ & $10,99 \mathrm{~b}$ \\
\hline FM & 389 & $571 \mathrm{~b}$ & 16,95 & 7,98 & $10,07 \mathrm{a}$ & $1.275,38 \mathrm{a}$ & $14,39 \mathrm{a}$ \\
\hline FB & 413 & $592 \mathrm{a}$ & 17,50 & 7,62 & $9,02 \mathrm{ab}$ & $1.183,32 \mathrm{ab}$ & $12,88 \mathrm{ab}$ \\
\hline FT & 411 & $572 b$ & 16,95 & 7,18 & $7,83 \mathrm{ab}$ & $1.090,91 \mathrm{ab}$ & $11,19 \mathrm{ab}$ \\
\hline \multicolumn{8}{|l|}{ Média (D) } \\
\hline D1 & 408 & $587 \mathrm{a}$ & 17,21 & 7,60 & 13,91 & $1.154,03$ & 12,53 \\
\hline D2 & 408 & $578 b$ & 16,98 & 7,56 & 13,82 & $1.111,36$ & 11,99 \\
\hline
\end{tabular}

NDPF - número de dias do plantio ao florescimento; NDPC - número de dias do plantio à colheita; DP - diâmetro do pseudocaule; NPC - número de penca por cacho; PC - peso do cacho; PP - peso de penca. Médias seguidas da mesma letra em uma mesma coluna não diferem estatisticamente entre si, pelo teste Tukey a $5 \%$. 


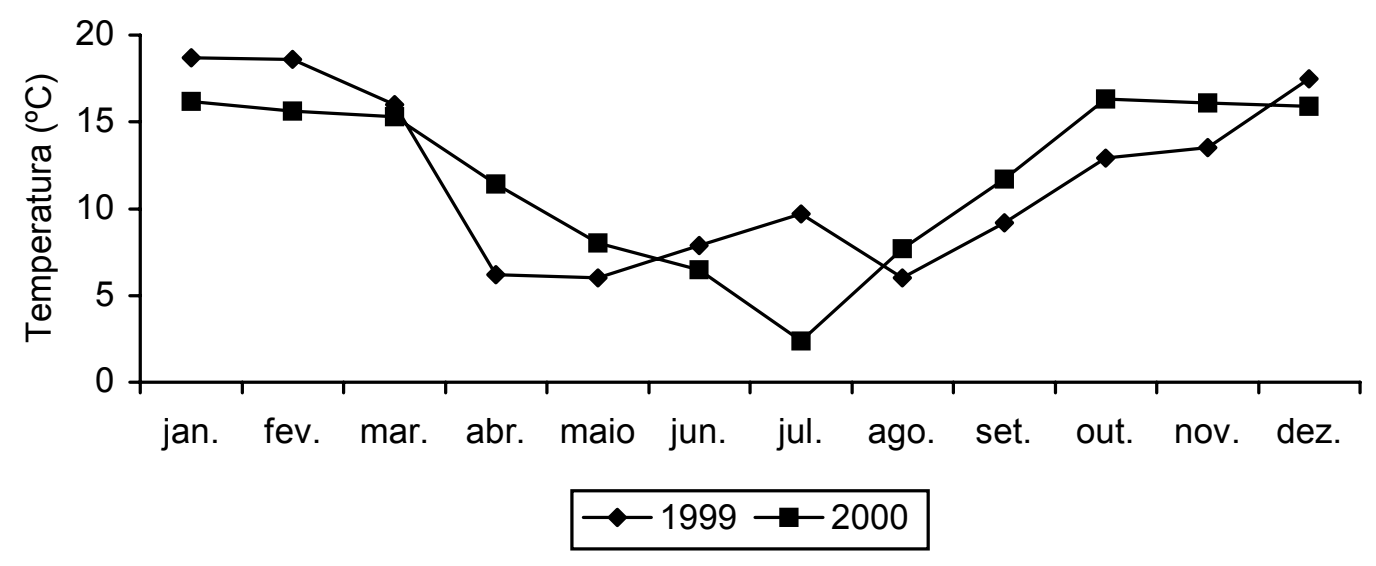

FIGURA 1. Médias mensais de temperaturas mínimas do ar.

Para peso de penca, houve efeito significativo para fertilização (freqüência), nos dois ciclos de cultivo, obtendo-se maiores valores com FM em relação à AC. PINTO et al. (2000) relatam que não houve interação entre o nitrogênio e o potássio para peso de penca. Essa variável quantitativa é considerada das mais importantes, pois se refere ao indicativo de mercado e ao direcionamento de consumo dos frutos. Os dados médios obtidos para peso de penca estão acima dos resultados obtidos por SILVA et al. (2000) e da mesma ordem dos apresentados por BORGES et al. (1994).

Com relação ao peso de cachos e produtividade, assim como ocorreu com o peso de pencas, a maior freqüência de fertirrigação (FM) promoveu valores significativamente maiores do que os obtidos com adubação convencional, havendo um incremento de $45 \%$ e de $31 \%$, para o primeiro e segundo ciclos, respectivamente. Isso ocorreu, provavelmente, devido à forma de aplicação e ao maior parcelamento de aplicação dos nutrientes.

A freqüência e a dosagem de fertilizantes não influenciaram no diâmetro, comprimento e teor de sólidos solúveis totais dos frutos (Tabela 4). Essas variáveis são mais relacionadas com as características intrínsecas da cultivar e servem como padrão para determinar o ponto de colheita (Normas do Ministério da Agricultura). Essa técnica discorda de SANTOS \& CHITARRA (2000) ao constatarem que o diâmetro e o comprimento dos frutos não são os melhores indicativos para a definição do ponto ideal de colheita. Para os autores, o número de dias do florescimento à colheita tem se revelado mais expressivo. Conforme BLEINROTH (1990), esse parâmetro pode ser mais influenciado pelas temperaturas ocorridas no ambiente, embora seja uma característica de qualidade muito importante, tornando os frutos mais adocicados.

Na Tabela 4, detecta-se o efeito da fertilização na relação polpa/casca, nos dois ciclos de cultivo. No primeiro ciclo, o tratamento FM apresentou média superior ao tratamento AC; no segundo ciclo, os tratamentos FT e FB apresentaram dados médios superiores aos obtidos com AC. Segundo CHITARRA \& CHITARRA (1990), a relação polpa/casca serve como indicativo do desenvolvimento do fruto, afirmando também que, quando essa relação for superior a 2, os mesmos podem ser colhidos. Possivelmente, os frutos dos tratamentos com fertirrigação se desenvolveram mais do que os frutos do tratamento com adubação convencional, pelas aplicações parceladas do nitrogênio e potássio, acelerando seu desenvolvimento e a maturação, como inclusive concluíram BORGES et al. (1997).

Também pela Tabela 4, verifica-se que não houve efeito significativo, no primeiro e no segundo ciclos, para os valores de $\mathrm{pH}$ do fruto, indicando que esse parâmetro não foi influenciado pela freqüência e doses de fertilizantes; entretanto, houve efeito na acidez do fruto, e a FM apresentou o menor valor para essa determinação, diferindo estatisticamente do tratamento FB. 
TABELA 4. Efeitos da freqüência de fertirrigação nitrogenada e potássica no diâmetro, comprimento, relação polpa/casca, sólidos solúveis totais, acidez e $\mathrm{pH}$ dos frutos da bananeira PrataAnã.

\begin{tabular}{|c|c|c|c|c|c|c|}
\hline Estatística & $\mathrm{DF}(\mathrm{cm})$ & $\mathrm{CF}(\mathrm{mm})$ & Polpa/Casca & S.S.T. $(\%)$ & Acidez $(\%)$ & $\mathrm{pH}$ \\
\hline \multicolumn{7}{|c|}{ Primeiro ciclo } \\
\hline Freqüência (F) & $2,62 \mathrm{~ns}$ & $1,53 \mathrm{~ns}$ & $3,59^{*}$ & $2,13 \mathrm{~ns}$ & $4,26^{*}$ & $2,12 \mathrm{~ns}$ \\
\hline Dose (D) & $0,41 \mathrm{~ns}$ & $2,90 \mathrm{~ns}$ & $0,01 \mathrm{~ns}$ & $0,22 \mathrm{~ns}$ & $0,01 \mathrm{~ns}$ & $0,22 \mathrm{~ns}$ \\
\hline F x D & 0,11 & $0,43 \mathrm{~ns}$ & $2,52 \mathrm{~ns}$ & $0,63 \mathrm{~ns}$ & $0,47 \mathrm{~ns}$ & $0,51 \mathrm{~ns}$ \\
\hline C.V.parcela & 7,95 & 5,39 & 21,12 & 8,14 & 14,79 & 3,23 \\
\hline C.V. subparcela & 5,32 & 3,56 & 14,90 & 5,78 & 9,87 & 2,35 \\
\hline \multicolumn{7}{|l|}{ Média $(\mathrm{F})$} \\
\hline $\mathrm{AC}$ & 35,22 & 100,46 & $2,34 b$ & 23,78 & $0,383 \mathrm{ab}$ & 4,20 \\
\hline FM & 35,65 & 103,41 & $3,11 \mathrm{a}$ & 23,06 & $0,364 a$ & 4,33 \\
\hline FB & 35,62 & 104,11 & $2,69 \mathrm{ab}$ & 23,34 & $0,453 b$ & 4,21 \\
\hline FT & 35,51 & 105,66 & $3,03 \mathrm{ab}$ & 24,36 & $0,394 \mathrm{ab}$ & 4,30 \\
\hline \multicolumn{7}{|l|}{ Média (D) } \\
\hline D1 & 35,85 & 104,91 & 2,78 & 23,52 & 0,399 & 4,25 \\
\hline D2 & 35,41 & 101,91 & 2,79 & 23,24 & 0,398 & 4,27 \\
\hline \multicolumn{7}{|c|}{ Segundo ciclo } \\
\hline Freqüência (F) & $0,94 \mathrm{~ns}$ & $3,43 \mathrm{~ns}$ & $3,79 *$ & $1,95 \mathrm{~ns}$ & $3,69^{*}$ & $2,84 \mathrm{~ns}$ \\
\hline Dose (D) & $1,95 \mathrm{~ns}$ & $0,03 \mathrm{~ns}$ & $0,05 \mathrm{~ns}$ & $0,80 \mathrm{~ns}$ & $0,08 \mathrm{~ns}$ & $0,33 \mathrm{~ns}$ \\
\hline F x D & $0,32 \mathrm{~ns}$ & $2,79 \mathrm{~ns}$ & $1,95 \mathrm{~ns}$ & $0,98 \mathrm{~ns}$ & $1,86 \mathrm{~ns}$ & $0,57 \mathrm{~ns}$ \\
\hline$\overline{C . V . p a r c e l a}$ & 3,25 & 4,64 & 20,90 & 4,56 & 13,20 & 4,55 \\
\hline C.V. subparcela & 1,74 & 4,43 & 16,90 & 3,67 & 10,70 & 3,55 \\
\hline \multicolumn{7}{|l|}{ Média $(\mathrm{F})$} \\
\hline $\mathrm{AC}$ & 35,92 & 100,50 & $2,56 \mathrm{~b}$ & 26,70 & $0,356 \mathrm{ab}$ & 4,30 \\
\hline FM & 35,75 & 111,00 & $2,65 \mathrm{ab}$ & 26,60 & $0,332 b$ & 4,21 \\
\hline FB & 36,14 & 106,99 & $3,10 \mathrm{a}$ & 25,80 & $0,403 \mathrm{a}$ & 4,33 \\
\hline FT & 35,30 & 107,25 & $3,15 \mathrm{a}$ & 25,50 & $0,376 \mathrm{ab}$ & 4,41 \\
\hline \multicolumn{7}{|l|}{ Média (D) } \\
\hline $\mathrm{D} 1$ & 36,04 & 107,70 & 2,67 & 26,00 & 0,378 & 4,25 \\
\hline $\mathrm{D} 2$ & 35,52 & 107,40 & 2,65 & 25,10 & 0,380 & 4,24 \\
\hline
\end{tabular}

DF - diâmetro dos frutos; CF - comprimento dos frutos; SST - sólidos solúveis totais. Médias seguidas da mesma letra em uma mesma coluna não diferem estatisticamente entre si, pelo teste de Tukey a 5\%.

\section{CONCLUSÕES}

A fertirrigação mensal foi mais eficiente sobre o peso de cachos, peso de pencas e produtividade comparada à adubação convencional (via solo).

Algumas fertirrigações promoveram valores de relação polpa/casca dos frutos superiores aos obtidos com a adubação convencional.

A acidez total titulável dos frutos nos tratamentos com fertirrigação mensal foi menor do que com fertirrigação trimestral.

A redução da dose de $\mathrm{N}$ e $\mathrm{K}$ em $50 \%$, independentemente da forma de aplicação, não exerceu efeito sobre a produção e a qualidade dos frutos da bananeira Prata-Anã. 


\section{AGRADECIMENTOS}

Ao CNPq, pela bolsa de estudo concedida durante o transcorrer do curso de pós-graduação do primeiro autor, e à FAPESP, pelo auxílio financeiro para a realização desta pesquisa.

\section{REFERÊNCIAS BIBLIOGRÁFICAS}

ALVES, E.J. A cultura da bananeira: aspectos técnicos, socioeconômicos e agroindustriais. 2. ed. Brasília: EMBRAPA/CNPMF, 1999. 585 p.

BLEINROTH, E.W. Matéria-prima. In: ITAL. Banana. 3. ed. Campinas, 1990. p.133-96.

BORGES, A.L.; SILVA; J.T.A. da; OLIVEIRA, S.L.; SOUTO, R.F.; ALVES, E.J. Doses de nitrogênio e potássio para bananeiras em áreas irrigadas no Norte de Minas Gerais. Cruz das Almas: EMBRAPA/CNPMF, 1994. 4 p.

BORGES, A.L.; SILVA, J.T.A. da; OLIVEIRA, S.L. de. Adubação nitrogenada e potássica para bananeira cv. Prata-Anã irrigada: produção e qualidade dos frutos no primeiro ciclo. Revista Brasileira de Fruticultura, Cruz das Almas, v.19, n.2, p.179-84. 1997.

CHITARRA, M.I.F.; CHITARRA, A.B. Pós-colheita de frutas e hortaliças: fisiologia e manuseio. Lavras: ESAL/FAEPE, 1990. 293 p.

COELHO, A.M. Fertigação. In: COSTA, E.F.; VIEIRA, R.F.; VIANA, P.A. (Ed.) Quimigação. Sete Lagoas: EMBRAPA/CNMS, 1994. p.201-27.

DOORENBOS, J.; KASSAM, A.H. Yield response to water. Rome: FAO (Irrigation and Drainage Paper 33), 1979. $306 \mathrm{p}$.

EPAMIG. Sistema de produção para a cultura da banana Prata-Anã. Belo Horizonte, 1996. 34 p. (Boletim Técnico)

FAO. Production Yearbook - 2000. Rome, 2002. 260 p. v.54, n.163.

FREUD, D.J.; LITTELL, R.C. SAS for linear models: a guide to the ANOVA and GLM procedures. Cary: SAS Institute, 1981.231 p.

GOMES, J.A.; NÓBREGA, A.C. Comportamento de cultivares e híbridos de bananeira na região produtora do Estado do Espírito Santo. Revista Brasileira de Fruticultura, Jaboticabal, v.22, n.1, p.113,2000 .

INSTITUTO DE ECONOMIA AGRÍCOLA (IEA). Previsão e estimativas de safras para o Estado de São Paulo. Revista de Economia Agrícola, São Paulo, v.8, p.25-9, 1997.

KELLER, J.; KARMELI, D. Trickle irrigation design. Glendora: Rain Bird Sprinkler Manufacturing Corporation, $1975.133 \mathrm{p}$.

LOPES, A.; ESPINOSA, J. Manual de nutricion y fertilizacion del banano. Quito:

CARBANA/INPOFOS, $1995.82 \mathrm{p}$.

OLLITA, A.F.L. Métodos de irrigação. São Paulo: Nobel, 1977. 267 p.

PINTO, J.M.; FLORI, C.M.; FARIA, C.M.B.; SILVA, D.J.; SOARES, J.M. Aplicação de nitrogênio e potássio via fertirrigação em bananeira. In: CONGRESSO BRASILEIRO DE ENGENHARIA AGRÍCOLA, 29., 2000, Fortaleza. Anais ... Fortaleza: Sociedade Brasileira de Engenharia Agrícola, 2000. 1 CD. 
PIZA JÚNIOR, C.T. A fruticultura na região Sudeste do Brasil. In: SEMINÁRIO DE FRUTICULTURA NA AMÉRICA LATINA, 1., 1997, Campinas. Anais... Campinas: Sociedade Brasileira de Fruticultura. p.3-52.

RAIJ, B. van; CANTARELLA, H.; QUAGGIO, J.A.; FURLANI, A.M.C. (Eds.) Recomendações de adubação e calagem para o Estado de São Paulo. 2.ed. Campinas: Instituto Agronômico \& Fundação IAC, 1996. 285 p. (Boletim Técnico 100).

SANTOS, E.da S.; CHITARRA, M.I.F. Relação entre a idade do cacho de banana "Prata-anã" à colheita e a qualidade dos frutos após a colheita. Lavras: ESAL/FAEP, 2000. 4 p.

SILVA, J.T.A.; BORGES, A.L.; MALBURG, J.L. Solos, adubação e nutrição da bananeira. Informe Agropecuário, Belo Horizonte, v.20, p.21-36, 1999.

SILVA, S. de O.; ROCHA, S.A.; ALVES, E.J.; CREDICO, M.D.; PASSOS, A.R. Caracterização morfológica e avaliação de cultivares e híbridos de bananeira. Revista Brasileira de Fruticultura, Jaboticabal, v.22, n.2, p.161-9, 2000.

SOTO, M. Bananas: cultivos y comercialización. 2.ed. San José: LIL, 1992. 674 p.

TRESSLER, D.J.; JOSLYN, M.A. Fruits and vegetable juice-processing technology. Westport: Connecticut AVI, 1961. $1.028 \mathrm{p}$. 